\title{
Welding of pipes in fixed position with internal anti-corrosion protection of joints
}

\author{
Elena Bogomazova ${ }^{1}$, Irina Ziyatdinova ${ }^{1}$, Dmitriy Aiduganov ${ }^{1 *}$, Anna Pershina $^{2}$ and Alexey Anikeyev ${ }^{2}$ \\ ${ }^{1}$ IPC LLC, Ivan Goncharov St., Bugulma, Tatarstan Republic, Russia, 423233 \\ ${ }^{2}$ Tomsk Polytechnic University, Lenin avenue, Tomsk, Russia, 634050
}

\begin{abstract}
The article reviews the weldability of clad steel used for protection of inner surface of oil-andgas pipelines from corrosion by different welding materials. It is indicated that during welding of the root pass by stainless electrodes in one pass the transition structures appear on the interface of two dissimelar metals. This process leads to the formaion of cracks. To reduce negative impact of the transition structures on the characteristics of welded joints it is recommended to weld the first two passes with strainless electrodes.
\end{abstract}

\section{Methods and materials}

The research was focused on butt joints of pipes made of low-alloyed ferritic-pearlitic steels A 516-55, 20, and $20 \mathrm{kt}$, with tips on the pipe ends made of a AISI 321 stainless steel [1]. Diameter of joined pipes $159 \mathrm{~mm}$.

The thickness of the pipe parent material was $6 \mathrm{~mm}$; cumulative thickness of stainless steel backing ring was $3.5 \mathrm{~mm}$. Welding was performed in 3 stages. Abutting member edges were prepared as per $\mathrm{C} 17$ standard 16037 [2] type.

Pipe joints were welded upwards using different electrodes in a fixed position with the weld procedure presented in Table 1.

Table 1. Weld procedure.

\begin{tabular}{|c|c|}
\hline $\begin{array}{l}\text { Procedure } \\
\text { number }\end{array}$ & Welding parameters \\
\hline 1 & $\begin{array}{l}\text { Root layer: electrode } \text { ЭA-395/9, diam. } 3.0 \\
\text { mm (I=75...85 A); Filler and cover layers: } \\
\text { electrode LB-52U, diam. } 3.2 \mathrm{~mm} \\
(\mathrm{I}=90 \ldots 110 \mathrm{~A})\end{array}$ \\
\hline 2 & $\begin{array}{l}\text { Root layer: electrode OK } 61.30 \text {, diam. } 2.5 \\
\text { mm (I=45...50 A); Filler and cover layers: } \\
\text { electrode LB-52U, diam. } 3.2 \mathrm{~mm} \\
(\mathrm{I}=90 \ldots 110 \mathrm{~A})\end{array}$ \\
\hline 3 & 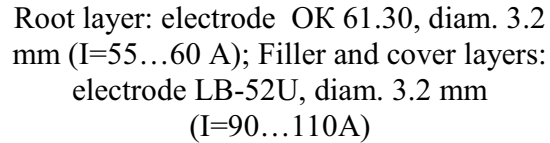 \\
\hline 4 & $\begin{array}{c}\text { Root and filler layers: electrode OK } 61.30 \\
\text { diam. } 2.5 \mathrm{~mm}(\mathrm{I}=45 \ldots 50 \mathrm{~A}) \text {; Cover layer: } \\
\text { electrode } \mathrm{LB}-52 \mathrm{U} \text {, diam. } 3.2 \mathrm{~mm} \\
(\mathrm{I}=90 \ldots 110 \mathrm{~A})\end{array}$ \\
\hline
\end{tabular}
uphill.
According to the first 3 options, the root pass was welded using an OK 61.30 high alloy electrode, having a chemical composition and mechanical properties similar to steel AISI 321, as well as ЭA-395/9 special composition electrodes, as recommended in the datasheets and specifications for welding two-layer steels having similar composition. The filling and capping layers were made using LB-52U electrodes designed for welding pipe steels such as A 516-55, 20, and others.

According to the fourth option, the second layer made by the same electrodes was laid on the root pass made by high-alloyed electrodes OK 61.30. Afterwards, the filling and capping layers were made by LB-52U electrodes.

The quality of welded joints was evaluated by means of visual and dimensional examination, radiographic control methods, and mechanical tests, such as static tension and static bending tests.

The appearing structures were studied using metallographic analysis of the welded joint cross-section and by measuring the micro hardness of the weld joint from the root pass to the capping layer.

The resistance of welded joints to pitting corrosion was evaluated after testing in accordance with standard $9.912[2]$.

\section{Experimental result}

When making the root pass with OK 61.30 electrodes, steady arc burning and satisfactory formation of the weld in the overhead and vertical positions were observed (Fig. 1, a).

In the course of overhead-position welding using ЭA-395/9 electrodes, proper formation of the opposite bead was achieved by increasing the welding current by $10 \ldots 15 \%$ of the amperage commonly accepted in general 
practice for the flat welding position. However, given such an increase in the amperage to weld the entire layer, a significant deformation is observed along the inner stainless steel ring perimeter, which leads to its bending into the pipe as well as long sections having poor penetration (Fig. 1, b).

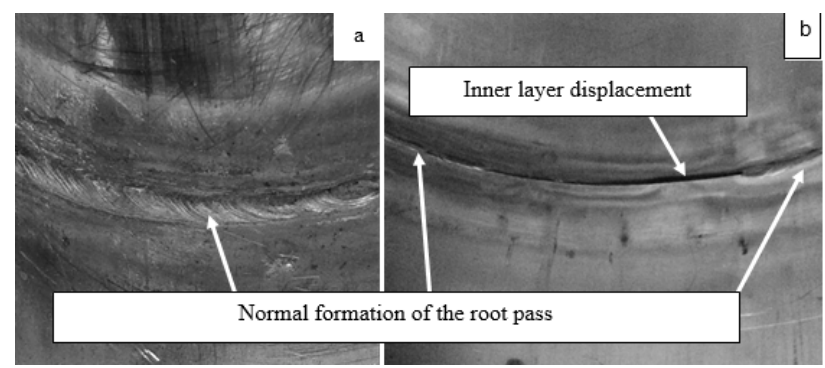

Fig. 1. Root pass: $a$ - normal formation, $b$ - a section with the inner layer displacement due to deformation caused by the welding thermal cycle.

To eliminate the effect of the guard ring edge bending inside the pipe, 2 ...3 tacks must be added along the perimeter of the joint. Figure 2 shows cross-sectional photographs of microscopic structure of welding joints.

Welding joints in dissimilar metal stir zone have a transitional layer of increased hardness and shortness. While making a root pass using OK 61.30 electrodes as per options 2 and 3, its depth of the residual austenitic layer is by one third or by half less than the corrosionresistant tip thickness, which provides forming of transition structures on pipe and backing ring metal boundary lines (Fig.2, b and c). The boundary line between the pipe and the tip represents the stress riser. If the stress riser is placed in the welding joint area with transition structures, cracks can appear in the welding joint.

While making a welding joint according to option 1, significant penetration of the root pass is not observed (Fig. 2, a), which can be related to the presence of 5\% refractory carbide-forming molybdenum in the austenitic electrodes. The depth of the corrosion-resistant layer of the welded joint exceeds the total thickness of the backing ring tips. The transition layer (fill) is located above the tip-pipe interface.

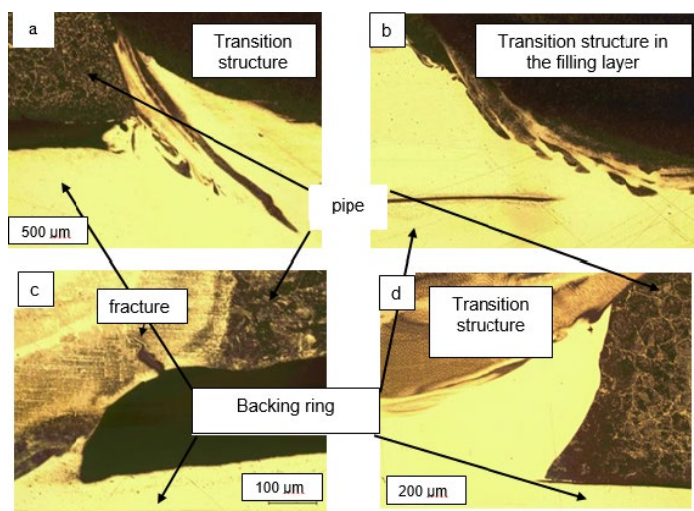

Fig.2. Cross-sectional representation of the microscopic structure of welding joints made according to option 1 (a), option 2 (b), option 3 (c), and option 4 (d).
In case of joint welding according to option 4 (the root pass and the filling layer were made by electrodes of austenitic content; the capping layer - by electrodes of ferrite-pearlite content), the elevation of corrosionresistant layer is observed, which provides shifting of transition structures in the thickness of the pipe metal root pass (Fig. 2, d).

The analysis of micro-hardness distribution along joint metal cross-section showed the increase of the average thickness level of transition layer content up to 400 HV (Fig. 3).

Negative structures formed during the stirring of corrosion-resistant and low-alloy steels are shifting from the pipe partition and ring border during the welding according to option 4 .

The presence of increased thickness areas on welding joints can lead to reduction of stress-strain properties of the welding joint.

Mechanical testing of welding joints was performed according to standard 6996 [3]. The samples were produced by the type XII.
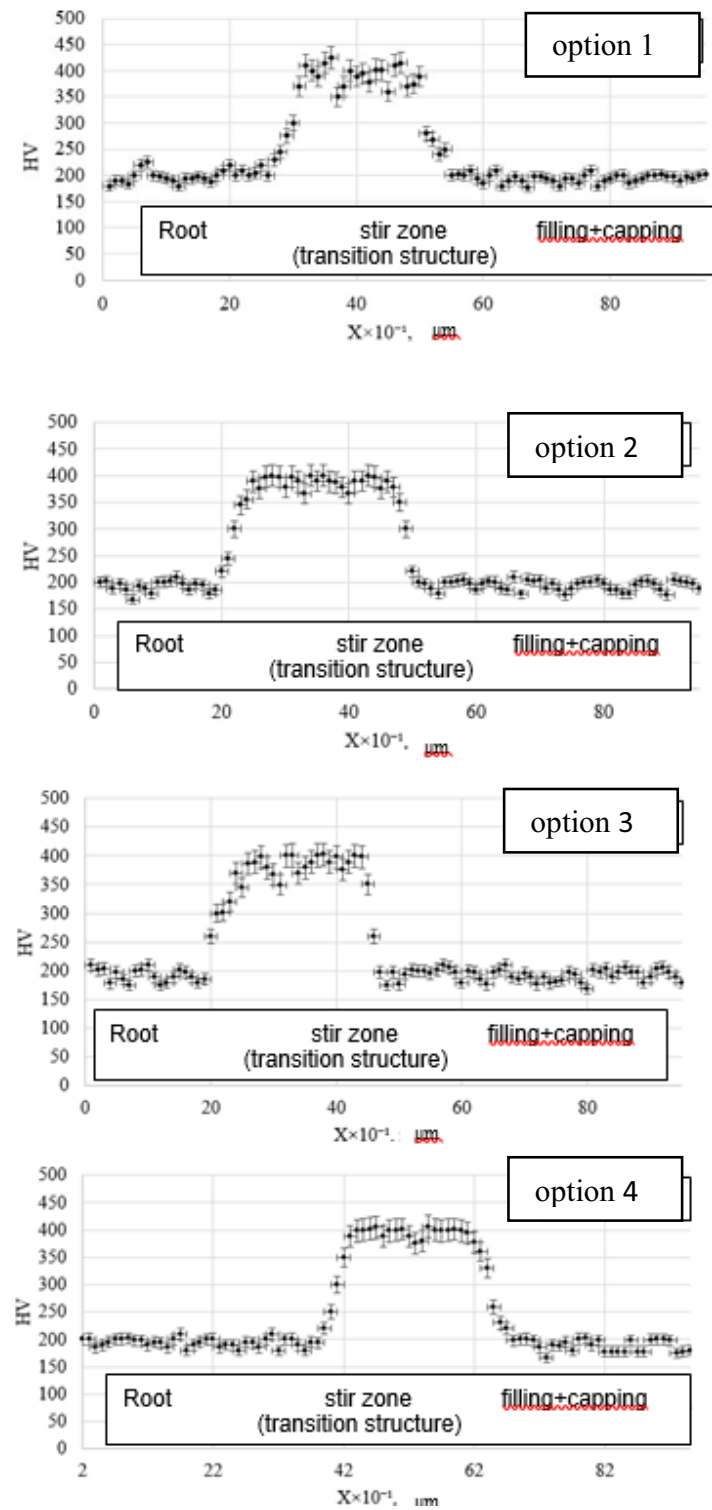

Fig.3. Graphs of micro-hardness distribution along the welding joint thickness. 
The capping layer was cleaned up to the parent material thickness. The backing ring was mechanically removed by cleaning up to the pipe parent material. The results of static tension test of all welding joints were satisfactory. The fracture appeared on the parent material; the breaking stress corresponded to the pipe parent material strength.

Welding joints made according to options 2 and 3 did not pass the slow-bend test with root being outwards. Joint fractures appeared when bending angle was no more than 50 degrees.

During slow-bend test of the welding joint made according to option 4, soft austenitic metal is present on the side of the root pass in the tensile zone, which allows achieving the required bending angle of 120 degrees with no fractures.

When testing pitting corrosion resistance of the welded joints, $50 * 50$ samples having thickness equal to the wall thickness were cut from the welded joints. Samples were weighed before the test, then immersed in a ferric chloride solution according to GOST 9.912 and kept there for 24 hours.

After exposure to the solution, the samples were dried, cleaned of rust, and weighed again.

Regardless of the combination of electrodes used, the average mass loss was $1.2 \mathrm{mg}$.

The loss of sample mass as a result of corrosion occurs due to the low-alloy layer.

The photos clearly show the darkening of the pipe's main layer and the layers made by the LB-52U electrodes (Fig. 4).

There are no signs of pitting corrosion on the root of the weld joint.

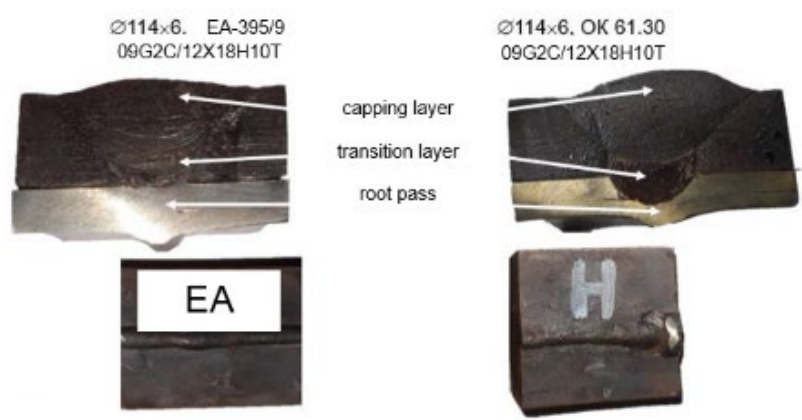

Fig. 4. How welded joints look like after pitting corrosion resistance tests.

\section{Conclusions}

Executing the seam root pass using 2.5 and $3.2 \mathrm{~mm} \mathrm{OK}$ 61.30 electrodes contributes to the formation of brittle structures when mixed with the LB-52U filling layer at the level of the interface between two dissimilar steels. Such welding joints predominantly do not pass mechanical slow-bend tests and fail to meet the requirements of corporate standard 00220368-011-2007 [4].

The use of ЭА-395/9 electrodes when welding pipelines are in a fixed position is challenging and requires highly skilled welders. Moreover, if the weld puddle retention in overhead position is necessary, the increase of welding current is required, which leads to deformation of protective corrosion-resistant ring and does not allow achieving satisfactory quality of the welding joint.

To achieve high-quality welding joint able to withstand operational loads, shifting the welding joint layer having transition structure from the border line between 2 details (pipe + ring), which comes as a stress riser, is required. While making of first two layers by austenitic electrodes, it is possible to achieve soft metal in the concentrator zone and required stress-strain properties of the welding joint.

\section{References}

1. Welded joints in steel pipelines. Main types, design elements and dimensions. Standard 16037-80 (1980)

2. Unified system of corrosion and ageing protection. Corrosion-resistant steels and alloys. Method of accelerated tests for resistance to pitting corrosion. Standard 9.912-89 (1989)

3. Welded joints. Methods of mechanical properties determination. ISO 4136-89 (1989)

4. Welding of dissimilar joints of vessels, apparatus and pipelines from carbon, low-alloyed, heatresistant, high-alloyed steels and iron-nickel and nickel-based alloys. STO 00220368-011-2007 (2007) 